\title{
Predicting pathology on small bowel capsule endoscopy: a good FIT
}

\section{다)(웅}

\author{
Authors \\ Institutions \\ 1 Department of Gastroenterology, Mercy University \\ Hospital, Cork, Ireland \\ 2 Department of Gastroenterology, Tallaght University \\ Hospital, Dublin, Ireland
}

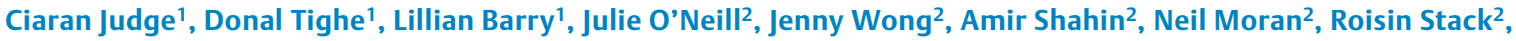
Mary Hussey², Niall Breslin², Anthony 0’Connor², Barbara Ryan², Martin Buckley², Deirde McNamara ${ }^{1}$ hood of small bowel pathology on SBCE. submitted 13.2.2019

accepted after revision 16.5.2019

Bibliography

DOI https://doi.org/10.1055/a-0990-9225 |

Endoscopy International Open 2019; 07: E1379-E1385

(c) Georg Thieme Verlag KG Stuttgart · New York eISSN 2196-9736

Corresponding author

Ciaran Judge, MB, BCh, BAO, Department of

Gastroenterology, Mercy University Hospital,

Cork, Ireland

Fax: +0214935200

Ciaranjudge@gmail.com

\section{ABSTRACT}

Background and study aims Small bowel capsule endoscopy [SBCE) has an established role in investigating suspected small bowel bleeding [SSBB). Identification of a biomarker to predict pathology would maximize utility of this valuable diagnostic modality. This study aimed to investigate if fecal immunochemical test [FIT) could predict likeli-

Patients and methods Patients referred for SBCE to investigate anaemia or suspected small bowel bleeding were prospectively recruited. All patients had negative upper and lower endoscopy prior to referral. A FIT $\geq 45 \mathrm{ug} \mathrm{Hb} / \mathrm{g}$ was considered positive. SBCE was positive if a potential source of SSBB was identified. The primary endpoint was correlation between FIT and positive SBCE. Secondary endpoints were correlation between anemia and SBCE and a combination of anemia plus FIT and SBCE.

Results Fifty-one patients were included in the final study cohort. $29.4 \%$ had a positive FIT, $33.3 \%$ were anemic, and $25.5 \%$ patients had significant SBCE findings. There was a statistically significant association between positive FIT and pathology on SBCE (OR 12, $95 \% \mathrm{Cl}[2.8-51.9$ ), $P=$ $0.001)$. Sensitivity and specificity of positive FIT in predicting SBCE findings were $69 \%$ and $84 \%$, respectively. A normal $\mathrm{Hb}$ had an NPV of $83 \%$ (OR 0.30, $P=0.09$ ). Combining $\mathrm{Hb}$ and FIT was statistically significant in predicting pathology on SBCE (OR 9.14, 67\% PPV, 82\% NPV, $P=0.025$ ).

Conclusion $\mathrm{FIT} \geq 45 \mathrm{ug} \mathrm{Hb} / \mathrm{g}$ is a useful tool in predicting small bowel pathology on SBCE. Use of this biomarker alone, or in combination with serum haemoglobin, has value as a screening tool and may help to better triage patients referred for SBCE.

\section{Introduction}

Evaluation of gastrointestinal bleeding with standard endoscopic and radiographic methods reveals an identifiable source in $90 \%$ to $95 \%$ of patients [1,2]. Up to $75 \%$ of the remaining cases of suspected small bowel bleeding (SSBB) are thought to originate in the small bowel $[3,4]$. Investigation of suspected small bowel bleeding often relies on persistent anemia identified on full blood count analysis and requires access to specialist centers and diagnostic techniques. Development of novel technology has provided noninvasive means of assessing small bowel pathology. However, access to these tests may be restricted by increasing demand and limited resources.

Small bowel capsule endoscopy (SBCE) uses wireless video technology to provide noninvasive endoluminal imaging of the small bowel, without need for insufflation of air or sedation. It is generally well tolerated by patients, and more sensitive than push enteroscopy, cross-sectional imaging and as good as device-assisted enteroscopy (DAE) in identifying small bowel pathology [5-7]. The European Society for Gastrointestinal Endoscopy (ESGE) recommends small bowel video capsule endoscopy as the first-line investigation in patients with SSBB, 
when small-bowel evaluation is indicated after a negative upper and lower endoscopy [7].

Diagnostic yield of SBCE is affected by delays between the suspected bleeding episode and time of investigation. Patients with ongoing overt or occult bleeding (fecal occult blood [FOB] positivity or unexplained iron deficiency anemia) are more likely to have pathology identified on SBCE. Conversely, diagnostic yield of SBCE has been reported to be reduced in patients who have experienced time delays between the investigation and diagnosis of SSBB [8-10]. It is therefore imperative that patients referred for investigation of suspected small bowel bleeding are triaged efficiently to maximize potential diagnostic yield and to guide further management.

Fecal immunochemical test (FIT) has an established role in investigating large bowel bleeding and is incorporated into several national bowel cancer screening programs [11]. It detects only human globin, which makes it more sensitive for colorectal lesions than guaiac tests, but theoretically less sensitive for proximal gastrointestinal lesions due to degradation of globin in transit [12].

Importantly, however, a positive FIT has been observed in $40 \%$ to $60 \%$ of patients who did not present with colorectal lesions upon subsequent investigation [13]. These data suggest that the source of the positive FIT may instead arise from small bowel pathology, perhaps due to incomplete globin degradation during gastrointestinal transit. FIT may, therefore, represent an opportunity as a useful screening biomarker to optimize triage and potentially filter inappropriate referrals for SBCE. It is also readily available in outpatient and GP settings, and could be easily incorporated into an SBCE referral algorithm.

Thus, the aim of this study was to investigate whether FIT could help predict likelihood of small bowel bleeding or other significant small bowel pathology at the time of SBCE. In doing so, we sought to contribute to the available body of data and to postulate whether FIT, alone or in combination with serum hemoglobin $(\mathrm{Hb})$, could be used to triage patients referred for investigation of suspected small bowel blood loss.

\section{Patients and methods}

\section{Patient selection criteria}

We conducted a prospective pilot study in a tertiary referral center in Dublin, Ireland. Candidates were invited to participate if they were adults ( $\geq 18$ years) referred for investigation of suspected small bowel bleeding following negative esophagogastroduodenoscopy (EGD) and colonoscopy. This included investigation for other possible causes of ferropenic anemia. These included duodenal biopsies and serology for identification of celiac disease; Campylobacter-like organism (CLO) test or urea breath test to identify Helicobacter pylori; or gastric biopsies and serology to determine presence of autoimmune gastritis. SSBB was subclassified according to ACG guidelines as overt small bowel bleeding (melena or hematochezia with a source identified in the small bowel) or occult (iron-deficiency anemia with or without guaiac-positive stools who are found to have a small bowel source of bleeding). Exclusion criteria included those under 18 years of age and those who declined or were unable to participate. Ethics was approved via the SJH/AMNCH Research Ethics Committee (REC Reference: 2017 -08).

\section{Study materials}

The FIT collecting tubes (OC-Sensor, EIKEN CHEMICAL, Tokyo, Japan) were quantitatively analyzed according to manufacturer's guidelines using latex agglutination immune-turbidimetry. A cut-off of $45 \mathrm{ug} \mathrm{Hb} / \mathrm{g}$ feces (equivalent to $225 \mathrm{ng} \mathrm{Hb} / \mathrm{mL}$ buffer) was chosen for our study, above which a FIT was deemed positive. This value was chosen as it is the standard cut-off used in the Irish National Bowel Screening Programme and is supported by international data as a cost-effective cut-off level [14-16].

SBCE investigations were performed using PillCam SB3 (Medtronic, Dublin) technology and analyzed by a single experienced gastroenterologist using Rapid Reader Version 8 software (Medtronic, Dublin). The reader is a professor in Gastroenterology with decades of experience in standard and capsule endoscopy. The reader was blinded to the FIT result. SBCE were deemed positive if potential sources of bleeding were identified, including angiodysplasia, neoplasms, ulcerative enteritis, or if visualized blood was observed. Anemia was defined based on local laboratory ranges for hemoglobin $(<13 \mathrm{~g} / \mathrm{dL}$ for males and $<12 \mathrm{~g} / \mathrm{dL}$ for females).

\section{Study protocol}

Two trained technicians who routinely perform SBCE were briefed on the study protocol. Prior to attending for their capsule endoscopy, patients were advised to take their last solid meal at lunchtime the day prior to the study, with clear fluids until midnight. Subjects then fasted until their procedure. On the day of their SBCE, patients were offered the opportunity to take part in the study. The purpose of the study, the specific protocol and alternatives to participation were clearly explained by the technicians. If willing to proceed, the patient was given a study-pack including an information leaflet, consent form, clinical questionnaire, FIT collecting tube and instructions. Eight sensors were placed on the abdominal wall and subjects were provided with a wireless recording device. Simethicone was given, they then swallowed the capsule and the wireless recorder was checked to ensure proper function. The recorder was worn for 8 hours during which time the patient could move freely and eat a light diet after 5 hours. The recording device was then returned to the gastroenterology department, along with the completed clinical questionnaire, FIT tube, and consent. Patients were then invited to provide a full blood count for analysis of serum hemoglobin. FIT samples were transferred immediately to the laboratory when received and stored at $0^{C}$, thereby minimizing time potential for degradation.

\section{Data collection}

Data were anonymized after collection and stored on a central data file on a single computer in a single hospital. Patients were assigned a study number to which the results of the relevant investigations were assigned. Clinical data collected included 
age, gender, use of medications including anti-platelets and iron supplementation, recent gastrointestinal bleeding, and relevant past medical history. Hb and FIT results were accessed using the electronic laboratory system and recorded under the study ID.

\section{Endpoints}

The primary endpoint was correlation between FIT and clinically significant findings on SBCE. Secondary endpoints included correlation between anemia and findings on SBCE; and between a combination of anemia plus FIT $(\mathrm{Hb}+\mathrm{FIT})$ and SBCE findings.

\section{Statistical analysis}

Continuous variables were expressed as medians (range). Correlation analysis using Pearson coefficient was used to identify possible associations between variables. Chi-squared test was used to assess differences between groups as appropriate. Mann Whitney $U$ test was performed to assess non-parametric samples. Associations were evaluated using univariate logistic regression analysis. Multivariate analysis was performed when two or more variables were significantly associated during univariate analysis. $P<0.05$ was considered significant in all analyses. Receiver operating curve (ROC) was calculated to evaluate the primary endpoint, and area under the curve (AUC) was calculated. Sensitivity, specificity, positive predictive value (PPV) and negative predictive value (NPV) were calculated. Statistical analysis was performed using SPSS (Build 16.0.0, IBM, New York, United States).

\section{Results}

A total of 54 patients were enrolled in the study. Fifty-one subjects were included in the final study cohort. The other three subjects were excluded due to inadequate luminal views in one case; one patient did not return a FIT; and one study was not performed as the patient could not swallow the capsule. FITs were returned within 48 hours in all cases, and immediately stored in a refrigerator at $0{ }^{\circ} \mathrm{C}$ until processed. $88.2 \%$ returned a $\mathrm{Hb}$, and $66.6 \%$ completed the questionnaire (relevant analysis was completed on available data only).

Median age was 60 years ( $18-85$ years), $37.3 \%$ were male and $41.2 \%$ of patients were $\geq 65$ years old ( $\downarrow$ Table 1 ). $38.9 \%$ $(n=22)$ reported overt gastrointestinal bleeding (melena or hematochezia) within the 3 months prior to testing, while $61.1 \%$ $(n=29)$ had been referred with suspected occult small bowel bleeding. Previous requirement for blood transfusion was reported by $30.6 \%, 38.9 \%$ reported recent (within 3 months) use of oral or intravenous iron supplementation, and $27.8 \%$ were taking one or more antiplatelet agents at time of testing. No patients were taking warfarin, and one patient was taking direct oral anticoagulants.

Median hemoglobin for the cohort at the time of SBCE was $13.0 \mathrm{~g} / \mathrm{dL}(7.1-15.7 \mathrm{~g} / \mathrm{dL})$, and $33 \%$ were anemic based on local laboratory parameters $(<13 \mathrm{~g} / \mathrm{dL}$ for males and $<12 \mathrm{~g} / \mathrm{dL}$ for females). Of the patients, $29.4 \%$ had FIT scores more than the predetermined cut-off of $\geq 45 \mathrm{ug} \mathrm{Hb} / \mathrm{g} .33 .3 \%$ of patients with
- Table 1 Patient Characteristics.

\begin{tabular}{|l|l|}
\hline Characteristics & Result \\
\hline Demographics & \\
\hline - Age (median [range]) & $60(18-85$ years $)$ \\
\hline - Sex (male) & $37.3 \%$ \\
\hline Medications & \\
\hline - Iron & $38.9 \%$ \\
\hline - Antiplatelets & $27.8 \%$ \\
\hline - Direct oral anticoagulant & $2.8 \%$ \\
\hline - Warfarin & $0 \%$ \\
\hline Clinical characteristics & \\
\hline - Chronic kidney disease & $2.8 \%$ \\
\hline - Overt bleeding (<3 months) & $38.9 \%$ \\
\hline - Previous transfusion & $30.6 \%$ \\
\hline Biochemical characteristics & \\
\hline - FIT score & $455 \mathrm{ug} \mathrm{Hb} / \mathrm{g}(0-4820 \mathrm{ug} \mathrm{Hb} / \mathrm{g})$ \\
\hline - Hemoglobin & $13.0 \mathrm{~g} / \mathrm{dL}(7.1-15.7 \mathrm{~g} / \mathrm{dL})$ \\
\hline FIT, fecal immunochemical test & \\
\hline
\end{tabular}

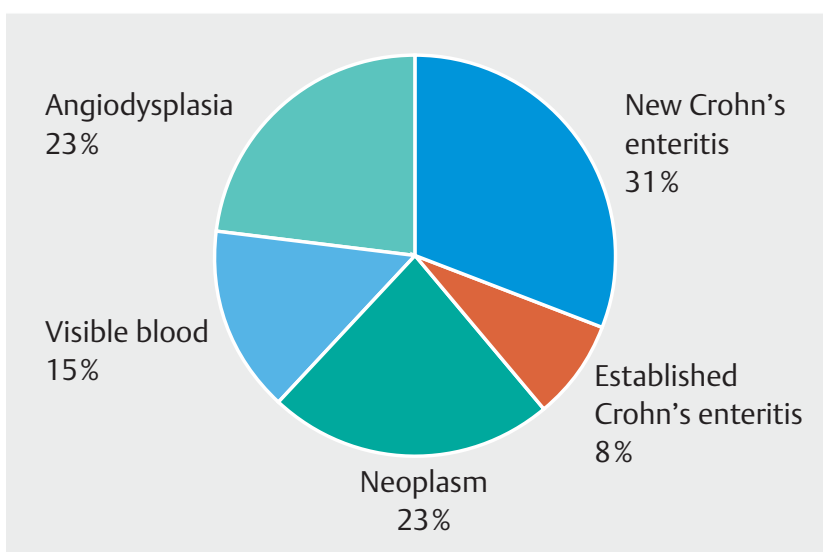

- Fig. 1 Findings on small bowel capsule endoscopy. Findings considered to be potential causes for suspected small bowel bleeding are shown.

positive FIT were male, and $60 \%$ of positive results were from patients $\geq 65$ years.

Of the patients, $25.5 \%$ had clinically significant findings on SBCE ( $\triangleright$ Fig. 1 ). These included four new diagnoses of ulcerative enteritis; three cases of angiodysplasia; three small-bowel neoplasms; and two findings of blood with no clear source ( $\triangleright$ Table 2). Of the patients, $53.8 \%$ with SB pathology were $\geq$ 65 years old, $69.2 \%$ were female and $33.3 \%$ reported overt bleeding within the last 3 months.

Regression analysis revealed a statistically significant correlation between positive FIT ( $\geq 45 \mathrm{ug} \mathrm{Hb} / \mathrm{g}$ ) and findings on 
- Table 2 Findings according to likelihood of causing SSBB

\begin{tabular}{|l|l|}
\hline Variable & N \\
\hline Probable causes & \\
\hline New ulcerative enteritis & 4 \\
\hline Established Crohn's enteritis & 3 \\
\hline Neoplasm & 3 \\
\hline Visible blood of unknown source & 2 \\
\hline Possible causes & \\
\hline Non-bleeding angiodysplasia & 3 \\
\hline Gastritis or gastric erosions & 2 \\
\hline Gastric angiodysplasia & 3 \\
\hline Portal hypertensive gastropathy & 1 \\
\hline SSBB, suspected small bowel bleeding & \\
\hline
\end{tabular}

- Table 3 Correlations of variables in predicting pathology on small bowel capsule endoscopy.

\begin{tabular}{|l|l|l|l|}
\hline Variable & PPV & NPV & P value \\
\hline Endpoints & & & \\
\hline - FIT $\geq 45 \mathrm{ug} \mathrm{Hb} / \mathrm{g}$ & $60 \%$ & $88.9 \%$ & $0.001^{*}$ \\
\hline - Anemia & $40 \%$ & $83 \%$ & 0.09 \\
\hline - FIT + anemia & $66.7 \%$ & $82.1 \%$ & $0.025^{*}$ \\
\hline $\begin{array}{l}\text { Other variables } \\
\text { - Antiplatelets }\end{array}$ & $20.0 \%$ & $73.1 \%$ & 0.514 \\
\hline $\begin{array}{l}\text { - Recent bleeding } \\
\text { - Iron supplementation }\end{array}$ & $21.4 \%$ & $72.7 \%$ & 0.506 \\
\hline $\begin{array}{l}\text { * Denotes statistically significant variables }(P<0.05) \text {. Chi-squared and uni- } \\
\text { variate logistic regression used for analysis. PPV, positive predictive value; } \\
\text { NPV, negative predictive value; FIT, fecal immunochemical test }\end{array}$ \\
\hline
\end{tabular}

SBCE $(R=0.51, P=0.0001)$. Positive FIT had a PPV of $60 \%$ and NPV of $88.9 \%$ in predicting SB pathology (OR 12, $95 \% \mathrm{Cl}$ [2.77-51.96], $P=0.001$ ) ( Table 3). There was a statistically significant reduction in mean FIT scores between patients with and without SB pathology $(1300.85[\mathrm{SEM} \pm 439.81 \mathrm{ug} \mathrm{Hb} / \mathrm{g}]$ versus 168.59 [SEM $\pm 129.85 \mathrm{uh} \mathrm{Hb} / \mathrm{g}$ ], $P=0.0001$ ) ( $\mathbf{F i g . 2}$ ). There were four false-negative results, which included an ulcerated submucosal mass, inflammatory distal ileal mass, proximal and jejunal angiodysplasia, and ulcerated anastomosis.

Sensitivity and specificity for FIT $\geq 45 \mathrm{ug} \mathrm{Hb} / \mathrm{g}$ in predicting SB pathology were $69.2 \%$ and $88.9 \%$, respectively. Calculation of ROC showed AUC to be 0.84 , suggesting this is a useful test (95\% Cl [0.70-0.97], $P=0.0003$ ) ( Fig. 3). Sensitivity and specificity varied with FIT cut-off points, as would be expected. Sensitivity for FIT>20ug Hb/g, > $45 \mathrm{ug} \mathrm{Hb} / \mathrm{g},>135 \mathrm{ug} \mathrm{Hb} / \mathrm{g}$, and $>200 \mathrm{ug} \mathrm{Hb} / \mathrm{g}$ was $84.6 \%, 69.2 \%, 69.2 \%$, and $61.5 \%$, respectively; while specificity was $60.5 \%, 88.9 \%, 89.5 \%$, and $89.5 \%$, respectively ( $\triangleright$ Table 4 ).

A combination of anemia and positive FIT was also statistically significant in predicting small bowel pathology on SBCE $(R=$

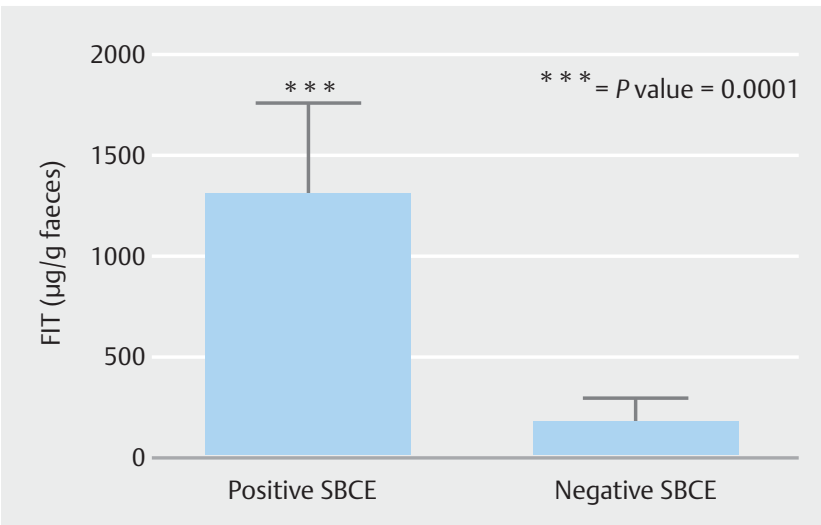

- Fig. 2 Mean \pm SEM FIT values. Mean FIT Values: Positive SBCE $=$ $1300.8( \pm 439.8 \mathrm{uh} \mathrm{Hb} / \mathrm{g})$; Negative SBCE $=168.6( \pm 129.9 \mathrm{ug} \mathrm{Hb} / \mathrm{g})$. *** $P=0.0001$

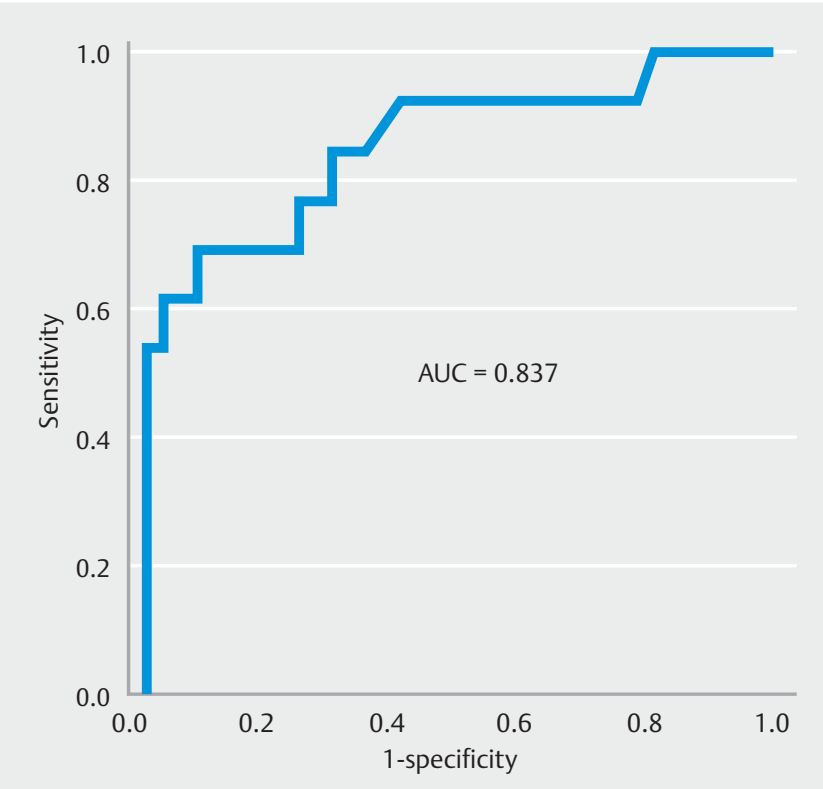

- Fig. 3 ROC of varying FIT values in prediction of pathology on SBCE.

0.39, $P=0.009)$. Hb + FIT had a PPV for SB pathology of $66.7 \%$, and an NPV of $82.1 \%$ (OR 9.14, 95\% Cl [1.39-60.12], $P=0.025)$.

Anemia at time of SBCE had a PPV for predicting SB pathology of $40 \%$, and an NPV of $83 \%$ (OR 3.33, $95 \%$ CI [0.81-13.66], $P=0.09)$. Multivariate analysis of statistically significant variables (FIT $\geq 45 \mathrm{ug} \mathrm{Hb} / \mathrm{g} ; \mathrm{Hb}+\mathrm{FIT}$ ) using multivariate linear regression revealed persistent statistical significance $(P<0.001)$.

Recent use of oral or intravenous iron was significantly associated with findings on SBCE $(P=0.005)$. There was no significant correlation between positive SBCE and concurrent use of antiplatelet medications, recent overt bleeding, or prior blood transfusion. We found no significant correlation between antiplatelet use and positive FIT ( $\triangleright$ Table 3 ).

SBCE revealed pathology proximal to the small bowel potentially accounting for SSBB in six further cases. These included 
- Table 4 Sensitivity and specificity of FIT values in Predicting SB pathology

\begin{tabular}{|c|c|c|}
\hline FIT Value (ug Hb/g) & Sensitivity & Specificity \\
\hline-1 & $100 \%$ & $100 \%$ \\
\hline 10 & $92.3 \%$ & $39.5 \%$ \\
\hline 20 & $84.6 \%$ & $60.5 \%$ \\
\hline 45 & $69.2 \%$ & $88.9 \%$ \\
\hline 135 & $69.2 \%$ & $89.5 \%$ \\
\hline 200 & $61.5 \%$ & $89.5 \%$ \\
\hline 400 & $53.8 \%$ & $97.4 \%$ \\
\hline FIT, fecal immunochemical test; SB, small bowel & \\
\hline
\end{tabular}

gastritis (4 cases), angiodysplasia in the stomach (1 case), and portal hypertensive gastropathy (1 case) ( $>$ Fig.4). Including these cases increased the diagnostic yield of our SBCE to $37.3 \%$. Evaluation of endpoints in these cases alone did not reveal any significant correlations.

\section{Discussion}

Investigation of suspected small bowel bleeding requires significant amounts of time and resources. The role of SBCE in diagnosis of SSBB has been well recognized in international guidelines, not only in identifying lesions potentially suitable for intervention, but also as negative tests have been shown to be associated with a lower risk of subsequent rebleeding [14]. Increasing awareness of the utility of SBCE has increased demand and therefore created a need for efficient methods of triaging referrals. Unfortunately, no validated selection tool for SBCE referral yet exists. A biomarker with strong positive predictive value would help prioritize patients who may require further intervention and management. Similarly, a biomarker with good negative predictive value may help screen inappropriate referrals, reduce costs and decrease the burden on busy departments.

FIT has been proven to be useful in detecting colorectal pathology, however a significant proportion of false positives raises the possibility that it may also be useful in detection of small bowel lesions [13]. There is limited data on this topic, however a recent meta-analysis of six publications suggested FIT is not a good predictor of findings on SBCE [15]. In the meta-analysis, sensitivity and specificity of FIT in prediction of SB pathology were 0.48 and 0.60 respectively, both considerably lower than our trial ( 0.69 and 0.89 at $>45 \mathrm{ug} \mathrm{Hb} / \mathrm{g}$ ). The studies included differed significantly from our trial, which may have contributed to this discrepancy. First, there were significant delays between analysis of FIT and completion of SBCE, in some cases up to 4 months [15]. In the meta-analysis, time between FIT to SBCE ranged between 3 days to 4 months, with an average lag of 1 to 2 weeks. Our average delay between FIT to SBCE was 24 hours. As has previously been reported, time between bleeding episode and SBCE can affect diagnostic yield,

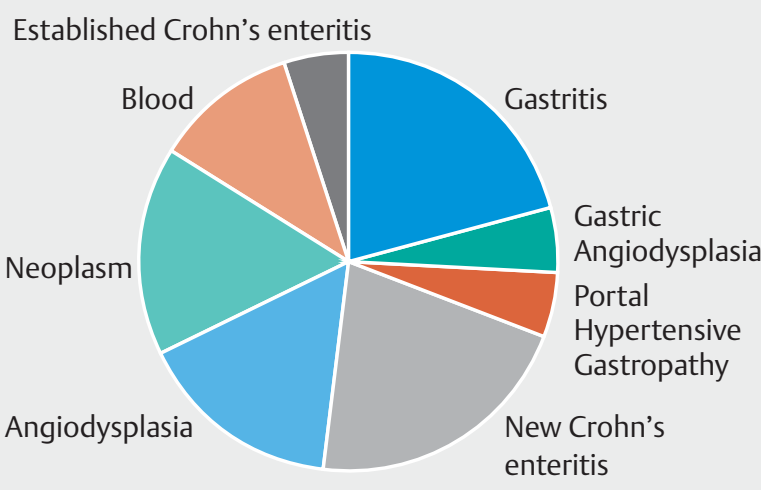

- Fig. 4 Findings on SBCE (including outside of SB).

therefore we maximized the potential correlation by minimizing delay [8-10]. This was a major strength of our study and supports the argument that to maximize efficacy of this resource, a positive FIT at time of referral should ensure urgent access to SBCE. Second, all studies in the meta-analysis used a FIT cutoff value of $100 \mathrm{ng} / \mathrm{mL}(20 \mathrm{ug} \mathrm{Hb} / \mathrm{g})$, whereas a cutoff value of $45 \mathrm{ug} \mathrm{Hb} / \mathrm{g}$ was used in the current study. There is a significant variation in cutoff values between centers and countries (many of which use a cutoff of $10 \mathrm{ug} \mathrm{Hb} / \mathrm{g}$ ) which remains a source of confusion. Results are difficult to standardize as different countries and hospitals use differing commercial products and analytical methods [16]. Optimal cutoffs may therefore vary from country to country, with further data required to identify an international standard. Despite this, our chosen cutoff value is used by the Irish BowelScreen programme and supported by data obtained by other groups [17-19]. Our study suggests that FIT $\geq 45 \mathrm{ug} \mathrm{Hb} / \mathrm{g}$ correlates well with findings on SBCE, and that a higher cutoff value results in better specificity ( $84.2 \%$ in our study vs $60 \%$ in the meta-analysis). This gives strength to the idea of FIT as a screening biomarker prior to SBCE.

Referral for SBCE is recommended for patients with iron deficiency anemia lacking an identifiable source following upper and lower gastrointestinal endoscopy. As mentioned above, there is often a significant delay between detection of anemia - frequently in the community setting - and completion of SBCE. We examined the relationship between $\mathrm{Hb}$ and SB pathology in our cohort. Anemia trended towards but did not reach statistical significance in predicting findings on SBCE (PPV 40\%, NPV 83\%, P=0.09). However, when we combined $\mathrm{FIT}>45 \mathrm{ug} \mathrm{Hb} / \mathrm{g}$ and anemia, this proved statistically significant in predicting pathology $(\mathrm{PPV}=66.7 \%(P=0.025), \mathrm{NPV}=82.1 \%$ $(P=0.004)$.

Incorporating a combination of FIT and $\mathrm{Hb}$ into the referral pathway could therefore be a useful tool in triaging referrals for SBCE. Adding FIT to the SBCE referral pathway would be relatively simple given its convenience and ready availability in the community. In the case of a positive FIT, our findings suggest a referral for urgent SBCE should be made. However, with a negative FIT, repeating an FBC to check for resolution of ane- 
mia may negate need for SBCE referral. If anemia is identified, referral could then be completed ( $>$ Fig.5). Through use of such an algorithm, there is potential to streamline the referral pathway for SBCE.

Utilization of FIT as a screening biomarker may also generate significant financial savings. According to an economic analysis by Palimaka et al, the average cost of a capsule endoscopy is approximately $\$ 950$ CAD (approximately $€ 633$ at 2015 exchange rate) [20], while the cost of FIT stands at approximately $€ 20$ to $€ 30$ [21]. Applying these data to our cohort, use of FIT>45 ug $\mathrm{Hb} / \mathrm{g}$ as a screening tool could have saved our department approximately $€ 19,456$ over the course of the study period, with four false-negative cases as described above.

Limitations of this study include relatively low numbers of patients. We are seeking to remedy this by developing a larger analysis to challenge our findings. Our study also revealed a relatively low diagnostic yield for SBCE versus some other studies. Our pathology detection rate was $25.5 \%$, considerably lower than in some studies included in the meta-analysis, some of which reached $63 \%$ [22]. This may reflect the lack of standardization when reporting capsule studies. Our figure reflected clinically significant findings as determined by a consultant gastroenterologist with expertise in SBCE, whereas some studies included all SB findings, some of which may be considered less likely to contribute to gastrointestinal bleeding [10]. The diagnostic performance in our study may also reflect inclusion of overt and occult bleeding cases within the same cohort, as overt bleeding has been shown to increase diagnostic yield. The average age of patients in the studies included in the meta-analysis was 64.1 years, whereas our patient cohort was younger, with an average age of 56.6 years, which may also have affected SBCE findings.

While our study supports use of FIT in detection of small bowel pathology, it does not support its use in identifying more proximal pathology. When including findings proximal to the small bowel, e.g. gastric pathology, our SBCE diagnostic yield increased to $37.3 \%$ which is in line with other publications. However, this resulted in disappearance of significant correlations, which may have been a factor in outcomes of previous studies. This supports the hypothesis that more proximal pa-

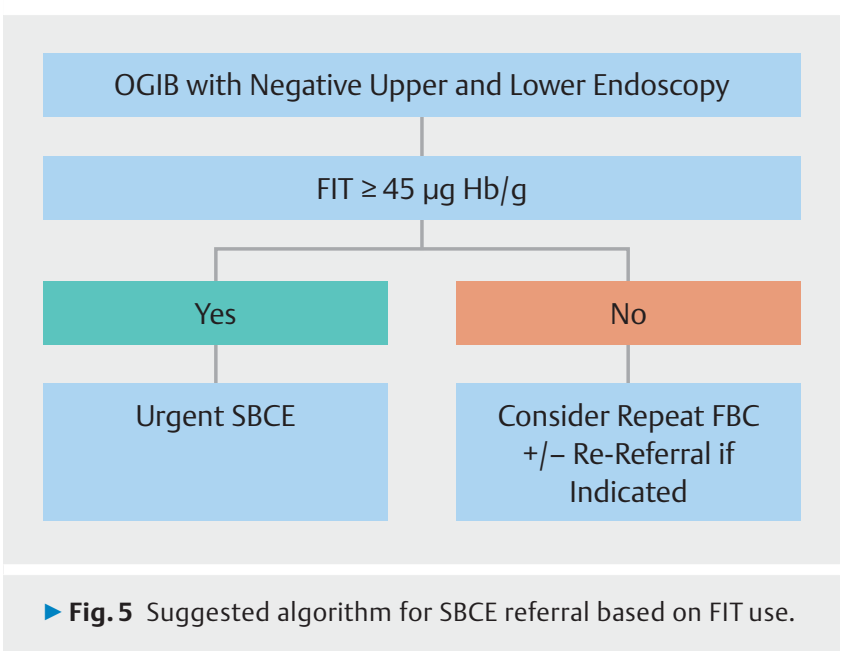

thology may result in denaturing of $\mathrm{Hb}$, but suggests FIT is still a useful tool in detection of SB pathology.

\section{Conclusion}

There is an established need for a biomarker to aid in investigation of suspected small intestinal bleeding. We found FIT to be sensitive and specific in predicting small bowel pathology on SBCE. Our findings suggest that FIT, possibly in conjunction with serum hemoglobin, is a useful and cost-effective screening tool for selection of patients who would benefit from this procedure.

\section{Competing interests}

None

References

[1] Gerson LB, Fidler JL, Cave DR et al. ACG Clinical Guideline: Diagnosis and Management of Small Bowel Bleeding. Am J Gastroenterol 2015; 110: $1265-1287$; quiz 1288

[2] Szold A, Katz LB, Lewis BS. Surgical approach to occult gastrointestinal bleeding. Am J Surg 1992; 163: $90-93$

[3] Tee H-P, Kaffes AJ. Non-small-bowel lesions encountered during double-balloon enteroscopy performed for obscure gastrointestinal bleeding. World J Gastroenterol 2010; 16: 1885-1889

[4] Pennazio M, Arrigoni A, Risio M et al. Clinical evaluation of push-type enteroscopy. Endoscopy 1995; 27: 164-170

[5] de Leusse A, Vahedi K, Edery J et al. Capsule endoscopy or push enteroscopy for first-line exploration of obscure gastrointestinal bleeding? Gastroenterology 2007; 132: 855- 862

[6] Teshima CW, Kuipers EJ, van Zanten SV et al. Double balloon enteroscopy and capsule endoscopy for obscure gastrointestinal bleeding: an updated meta-analysis. J Gastroenterol Hepatol 2011; 26: 796 801

[7] Harbord M, Annese V, Vavricka SR et al. Theffirst European evidencebased consensus on extra-intestinal manifetations in inflammatory bowel disease. J Crohns Colitis 2016; 10: 239-254

[8] Pennazio M, Santucci R, Rondonotti E et al. Outcome of patients with obscure gastrointestinal bleeding after capsule endoscopy: report of 100 consecutive cases. Gastroenterology 2004; 126: 643-653

[9] Singh A, Marshall C, Chaudhuri B et al. Timing of video capsule endoscopy relative to overt obscure GI bleeding: implications from a retrospective study. Gastrointest Endosc 2013; 77: 761 - 766

[10] Katsinelos P, Chatzimavroudis G, Terzoudis S et al. Diagnostic yield and clinical impact of capsule endoscopy in obscure gastrointestinal bleeding during routine clinical practice: a single-center experience. Med Princ Pract Int J Kuwait Univ Health Sci Cent 2011; 20: 60 - 65

[11] Navarro M, Nicolas A, Ferrandez A et al. Colorectal cancer population screening programs worldwide in 2016: An update. World J Gastroenterol 2017; 23: $3632-3642$

[12] Lin JS, Piper MA, Perdue LA et al. Screening for colorectal cancer: updated evidence report and systematic review for the US Preventive Services Task Force. JAMA 2016; 315: 2576-2594

[13] Park JJ, Cheon JH. §\#/ITL\#§ Small bowel evaluation in asymptomatic fecal immunochemical test-positive patients with a negative colonoscopy: is it necessary? Dig Dis Sci 2011; 56: $2773-2775$ 
[14] Pennazio M, Spada C, Eliakim R et al. Small-bowel capsule endoscopy and device-assisted enteroscopy for diagnosis and treatment of small-bowel disorders: European Society of Gastrointestinal Endoscopy (ESGE) Clinical Guideline. Endoscopy 2015; 47: 352 - 386

[15] Yung DE, Vijayan S, Avni T et al. Fecal occult blood testing for the prediction of small-bowel pathology detected by capsule endoscopy: a systematic review and meta-analysis. Ann Gastroenterol Q Publ Hell Soc Gastroenterol 2017; 30: 186- 191

[16] Ransohoff DF, Sox HC. Clinical practice guidelines for colorectal cancer screening: new recommendations and new challenges. JAMA 2016; 315: 2529-2531

[17] Mowat C, Digby J, Strachan JA et al. Faecal haemoglobin and faecal calprotectin as indicators of bowel disease in patients presenting to primary care with bowel symptoms. Gut 2016; 65: 1463 - 1469

[18] Guidelines for Quality Assurance in Colorectal Screening. Second Edition (Internet). National Screening Service, Available from: https:// www.bowelscreen.ie/_fileupload/Documents/BS\%20-\%20Guidelines
\%20for\%20Quality\%20Assurance\%20in\%20Colorectal\%20Screening\% 20-\%202nd\%20EDITION\%20(web).pdf

[19] Gibson DJ, Nolan B, Rea J et al. A prospective study of faecal immunochemical testing following polypectomy in a colorectal cancer screening population. Frontline Gastroenterol 2018; 9: 295-299

[20] Palimaka S, Blackhouse G, Goeree R. Capsule endoscopy in the assessment of obscure gastrointestinal bleeding: an economic analysis. Ont Health Technol Assess Ser 2015; 15: 1-32

[21] Meulen MP van der, Kapidzic A, Leerdam ME van et al. Do men and women need to be screened differently with fecal immunochemical testing? a cost-effectiveness analysis Cancer Epidemiol Biomark Prev Publ Am Assoc Cancer Res Cosponsored Am Soc Prev Oncol 2017; 26: $1328-1336$

[22] Shiotani A, Tarumi K, Honda K et al. Application of fecal hemoglobinhaptoglobin complex testing for small bowel lesions. Scand J Gastroenterol 2014; 49: 539-544 